\title{
Research the Effect of Process Parameters on Friction Stir Welded AA6063-ETP Copper joint using Taguchi Technique
}

\author{
Nitin Panaskar, Ravi Terkar
}

\begin{abstract}
Aluminium and copper, or their combination finds application in heat sinks because of their excellent thermal conductivity. In the present study, Al-6063 and ETP copper were lap welded using friction stir welding wherein the aluminum alloy plate was placed on top of the copper plate. The optimum process parameters were found using Taguchi L9 orthogonal array. The process parameters namely tool rotational speed, tool traverse speed and thickness of zinc inter-filler material were considered. The optimal process parameters were ascertained with respect to the thermal conductivity of weld. The predicted optimum value of thermal conductivity was verified by conducting the confirmation run using the optimal parameters. Analysis of variance depicted that all the three process parameters were significant, wherein the tool rotational speed and the tool traverse speed were the most dominant factors contributing to thermal conductivity.
\end{abstract}

Index Terms-Friction stir welding, AA6063, ETP copper, process parameters, Taguchi technique

\section{INTRODUCTION}

Aluminium and copper joining have numerous applications in automotive, HVAC and refrigeration industries [1, 2]. Joining of 6000 series aluminium alloys to copper find application in manufacturing of heat sinks due to their excellent thermal, electrical and anti-corrosion properties [3]. Al 6063 is usually used in heat sink applications because of its high thermal conductivity, tensile strength, and hardness. It is preferred for complex cross sections and easy to anodize, making it a favorable choice for heat sink applications $[4,5]$. AA 6063 has excellent corrosion resistance and good weld ability. The thermal conductivity can be further improved by adding Boron and Titanium [6]. An improvement of $13 \%$ and $6 \%$ in thermal conductivity was obtained with the addition of $0.05 \%$ of Boron and $0.3 \%$ of Titanium respectively [10]. Copper is another preferred material for heat sinks, and has approximately twice the conductivity of aluminium, but is three times denser and expensive than aluminium. Therefore industries are leaning towards substituting the copper parts with aluminium, either partially or entirely, to decrease the cost $[7,8]$. For an economical heat exchanger, it is essential to weld aluminium and copper, where the copper part will

Revised Version Manuscript Received on September 16, 2019.

Nitin Panaskar, Mukesh Patel School of Technology Management and Engineering, NMIMS University, Vile Parle, Mumbai- 400056, Maharashtra, India.

(Email: njpanaskar@gmail.com)

Ravi Terkar, Mukesh Patel School of Technology Management and Engineering, NMIMS University, Vile Parle, Mumbai- 400056, Maharashtra, India.

(Email: ravi.terkar@nmims.edu) reduce the temperature in high load areas whereas for the moderate and low load areas, the aluminium will suffice the heat transfer requirement. However, the differences in physical especially thermal , and chemical properties in case of dissimilar metal joining pose serious problems. The usual methods used to join aluminium to copper are friction welding [9, 10], ultrasonic welding [11], and laser welding [12]. Aluminium and copper are difficult to lap weld because of their dissimilar physical properties. During the welding process, the heat and liquefaction result in formation of intermetallic compounds (IMCs). Thick layers of intermetallic layers comprises of microcracks which decrease the strength of the joint. A thick layer of IMC will form crack and affect the mechanical properties unfavorably. It is hard to control the thickness of the inter-metallic compound layers $[13,14]$. Friction Stir Welding (FSW) is a newer technique employed to join aluminium and copper feasibly. FSW process was invented and developed by W.M. Thomas et al at The Welding Institute (TWI) in Cambridge, UK in 1991 [15]. This process was largely used for joining pure aluminium and its alloys [16]. FSW is employedto produce different types of joints, typically butt joints and lap joints. Recently, some studies have demonstrated the use of an intermediate layer such as zinc which is found to be compatible with both aluminium and copper $[17,18]$. This addition of intermediate layer can reduce the magnitude of inter-metallic compounds.

From the existing literature [19-22] the FSW process parameters such as tool rotational speed and transverse speed have significantly effect on the weld quality. Further, few studies concerning dissimilar metal welding, an additional process parameter namely inter-filler material of specific thickness was found to significantly affect the weld quality $[17,23]$. Preliminary experiments were performed using 3 $\mathrm{mm}$ thick plates of AA6063 aluminium alloy and ETP copper to fix the operational range of process parameters.

Taguchi technique is an efficient problem solving method to improve the product and process performance with significantly reduced time and cost of experimentation, which helps in production of superior quality products with low cost. It provides a methodical approach to optimize the design for performance, quality and cost. Taguchi method that combines the design of experiments (DOE) and the concept of quality loss function, is widely used in the robust 
design of processes and. products.

The steps are to be followed for optimization of process parameter are [24] :

1. Determination of the quality characteristic to be optimized.

2. Identification of the noise factors and test conditions.

3. Identification of the control factors and their alternative levels.

4. Design of the matrix experiment and resolution of the data analysis process.

5. Conduction the matrix experiment.

6. Analysis of the data and determination of optimal levels for control factors.

7. Prediction of the performance at these levels.

8. Verification of the optimum design parameters through the confirmation test.

\section{MATERIALS AND METHODOLOGY}

AA6063 and ETP copper sheets, both $3 \mathrm{~mm}$ thick, $130 \mathrm{~mm}$ in length and $90 \mathrm{~mm}$ in width, were selected for producing an intermediate layer. Heat treated H13 steel tools were used as shown in Figure 1.

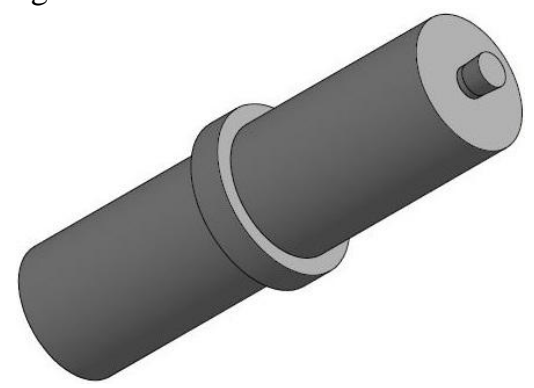

Figure 1. Tool for FSW process

Four distinct tools with pin lengths of $4.4 \mathrm{~mm}, 4.6 \mathrm{~mm}, 4.8$ $\mathrm{mm}$ and $4.94 \mathrm{~mm}$ were used to attain $50 \%$ penetration in the bottom copper material. The tool pin profile was inverse conical with top and bottom diameters $5.4 \mathrm{~mm}$ and $6 \mathrm{~mm}$ respectively. A flat shouldered tool of $24 \mathrm{~mm}$ diameter was used and the shoulder penetration of $0.1 \mathrm{~mm}$ was used for producing adequate frictional heat for welding. The work pieces were placed on a mild steel base plate and firmly clamped. Experiments were conducted with different tool rotational speed, tool traverse speed, and zinc foil thickness as shown in Table I. The chemical composition of the base metals is shown in Table II. The mechanical and thermal properties of the base metals are shown in. Table III.

The measurement of thermal conductivity of weld was carried out with a simple set-up which consists of a electrically operated steam generator, a steam conducting pipe, a steam chamber, and a container to collect water, as shown in Figure 2.

The following assumptions are made in measurement of thermal conductivity

1. The effect of film coefficient is neglected.

2. The temperature of steam is assumed to be $100^{\circ} \mathrm{C}$

3. The steam is assumed to be saturated

4. The ice is assumed to be melting at and from $0^{\circ} \mathrm{C}$

5. The melting of ice due to atmosphere is neglected lap joints. $0.2 \mathrm{~mm}$ and $0.4 \mathrm{~mm}$ thick foils of zinc were used as

I. Process parameters and their levels.

\begin{tabular}{llll}
\hline Level & $\begin{array}{l}\text { A } \\
\text { Rotational } \\
\text { speed } \\
(\mathrm{rpm})\end{array}$ & $\begin{array}{l}\text { B } \\
\text { Traverse } \\
\text { speed } \\
(\mathrm{mm} / \mathrm{min})\end{array}$ & $\begin{array}{l}\text { C } \\
\text { Thickness } \\
\text { of zinc } \\
\text { foil }(\mathrm{mm})\end{array}$ \\
\hline Level 1 & 1000 & 5 & 0 \\
Level 2 & 1200 & 10 & 0.2 \\
Level 3 & 1400 & 15 & 0.4 \\
\hline
\end{tabular}

The steam generator is attached to the box with the conducting pipe.. The weld sample was placed on top of the slot. The steam generator is switched on to generate steam, which passes to the steam chamber through the conducting pipe. The steam chamber is allowed to completely fill with steam for about 5 minutes for the system to reach steady state. A small opening is provided in the steam chamber to vent out water formed due to the condensation of steam. After 5 minutes, an ice block is placed on top of the weld surface. The ice block is shielded by an acrylic enclosure to prevent the heat transfer between ice and the atmosphere. The ice is allowed to melt for a fixed period of time. The water formed by melting of the ice is collected in the container and measured. The thermal conductivity of weld is calculated on the basis of the recorded volume of water.

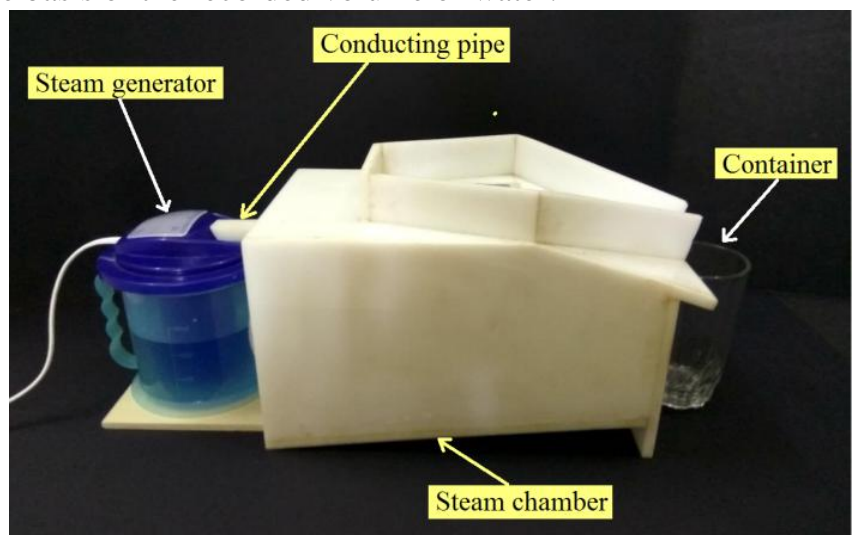

Figure 2. Set-up for measuring thermal conductivity of weld

We use the equation for heat transfer

$$
\frac{d Q}{d t}=k \cdot A \cdot \frac{d T}{d x}
$$

where dQ is amount of heat, $\mathrm{k}$ is thermal conductivity constant of sample, dT is the temperature difference, $\mathrm{dx}$ is the thickness of the material, A is the area of the ice in contact with the weld surface, and dt is time required for melting.

$$
\begin{gathered}
k=\frac{d Q}{d t} \frac{d x}{d T} \frac{1}{A} \\
d Q=m L_{f}
\end{gathered}
$$

where $\mathrm{L}_{\mathrm{f}}$ is the latent heat of fusion for melting/freezing, which is $334 \mathrm{~kJ} / \mathrm{kg}$ for water, and $\mathrm{m}$ is the mass of ice converted to water.

$$
\begin{gathered}
k=\frac{m}{d t} \frac{L_{f}}{A} \frac{d x}{d T} \\
k=\frac{m}{d t} \frac{(334)}{A} \frac{d x}{100}
\end{gathered}
$$


II. Main chemical compositions of the base metals

\begin{tabular}{llllll}
\hline $\begin{array}{l}\text { Sheet } \\
\text { Metal }\end{array}$ & Al & Cu & Mg & Mn & Zn \\
\hline $\mathrm{Al} 6063$ & Base & 0.08 & 4.8 & 0.8 & 0.1 \\
$\mathrm{ETP} \mathrm{Cu}$ & 0.02 & Base & - & - & 4.7 \\
\hline
\end{tabular}

III. Mechanical and thermal properties of the base metals

\begin{tabular}{llll}
\hline $\begin{array}{l}\text { Sheet } \\
\text { Metal }\end{array}$ & $\begin{array}{l}\text { Tensile } \\
\text { strength } \\
\text { (MPa) }\end{array}$ & $\begin{array}{l}\text { Microhardness } \\
(\mathbf{H V})\end{array}$ & $\begin{array}{l}\text { Thermal } \\
\text { conductivity } \\
\text { (W/(mK)) }\end{array}$ \\
\hline $\mathrm{Al} 6063$ & 160 & $80-85$ & 208 \\
$\mathrm{ETP} \mathrm{Cu}$ & 250 & $85-90$ & 392 \\
\hline
\end{tabular}

\section{RESULTS AND DISCUSSION}

\section{A. Signal to noise ratio}

Taguchi method uses the $\mathrm{S} / \mathrm{N}$ ratio to measure the deviation of the quality characteristic from the preferred value. The $\mathrm{S} / \mathrm{N}$ ratio characteristics can be separated into three modes: the nominal is better, the smaller is better, and the larger is better. In the present work, the objective is to maximize the thermal conductivity of the weld through optimum FSW process parameters, larger is better characteristic is used. The formula used for computing the $\mathrm{S} / \mathrm{N}$ ratio is given below :

$$
\frac{S}{N}=-10 \log _{10} \frac{1}{N} \sum_{i=1}^{n} \frac{1}{y_{i}{ }^{2}}
$$

where $y_{i}$ is the value of thermal conductivity of the weld for the $i^{\text {th }}$ experiment, $n$ is the number of experiments and $\mathrm{N}$ is the total number of data points.

The thermal conductivity of the welded joints is analyzed to understand the effect of the process parameters. The analysis is done using the MINITAB 18 software. Table IV. shows the $\mathrm{S} / \mathrm{N}$ response for the mean thermal conductivity parameters.

\begin{tabular}{cccccc}
\multicolumn{5}{c}{ IV. S/N response for the mean thermal conductivity } \\
\hline Sr. & A & B & C & Mean & Signal \\
No. & $\begin{array}{c}\text { Rotational } \\
\text { Speed } \\
\text { (rpm) }\end{array}$ & $\begin{array}{c}\text { Traverse } \\
\text { Speed } \\
(\mathrm{mm} / \mathrm{min})\end{array}$ & $\begin{array}{c}\text { Zinc foil } \\
\text { Thickness } \\
(\mathrm{mm})\end{array}$ & $\begin{array}{c}\text { Thermal } \\
\text { Conductivity } \\
\text { W/(m.K) }\end{array}$ & to noise \\
Ratio \\
\hline 1 & 1000 & 5 & 0 & 298.5 & 49.49 \\
2 & 1000 & 10 & 0.2 & 294.6 & 49.38 \\
3 & 1000 & 15 & 0.4 & 277.2 & 48.85 \\
4 & 1200 & 5 & 0.2 & 285.0 & 49.09 \\
5 & 1200 & 10 & 0.4 & 272.8 & 48.71 \\
6 & 1200 & 15 & 0 & 266.5 & 48.51 \\
7 & 1400 & 5 & 0.4 & 270.7 & 48.65 \\
8 & 1400 & 10 & 0 & 272.5 & 48.70 \\
9 & 1400 & 15 & 0.2 & 260.1 & 48.30 \\
\hline
\end{tabular}

A higher $\mathrm{S} / \mathrm{N}$ ratio implies better quality characteristics. On the basis of $\mathrm{S} / \mathrm{N}$ ratio values, the optimal level setting was achieved at rotational speed of $1000 \mathrm{rpm}\left(\mathrm{A}_{1}\right)$, transverse speed of $5 \mathrm{~mm} / \mathrm{min}\left(\mathrm{B}_{1}\right)$, and zinc foil thickness of $0.2 \mathrm{~mm}$ $\left(\mathrm{C}_{2}\right)$. The response table for $\mathrm{S} / \mathrm{N}$ ratio and mean effect are given in Table $\mathrm{V}$. and Table VI. respectively. The main effects plot for means and $\mathrm{S} / \mathrm{N}$ ratios are given in Figure 3. and Figure 4. respectively.

V. Response Table for Means

\begin{tabular}{llll}
\hline Level & A & B & C \\
\hline 1 & $\mathbf{2 9 0 . 1}$ & $\mathbf{2 8 4 . 8}$ & 279.2 \\
2 & 274.8 & 280.0 & $\mathbf{2 7 9 . 9}$ \\
3 & 267.8 & 267.9 & 273.6 \\
Delta & 22.3 & 16.8 & 6.3 \\
Rank & 1 & 2 & 3 \\
\hline
\end{tabular}

VI. Response Table for Signal to Noise Ratios :

Larger is better

\begin{tabular}{llll}
\hline Level & $\mathrm{A}$ & $\mathrm{B}$ & $\mathrm{C}$ \\
\hline 1 & $\mathbf{4 9 . 2 5}$ & $\mathbf{4 9 . 0 8}$ & 48.91 \\
2 & 48.78 & 48.94 & $\mathbf{4 8 . 9 3}$ \\
3 & 48.55 & 48.56 & 48.74 \\
Delta & 0.69 & 0.53 & 0.19 \\
Rank & 1 & 2 & 3 \\
\hline
\end{tabular}

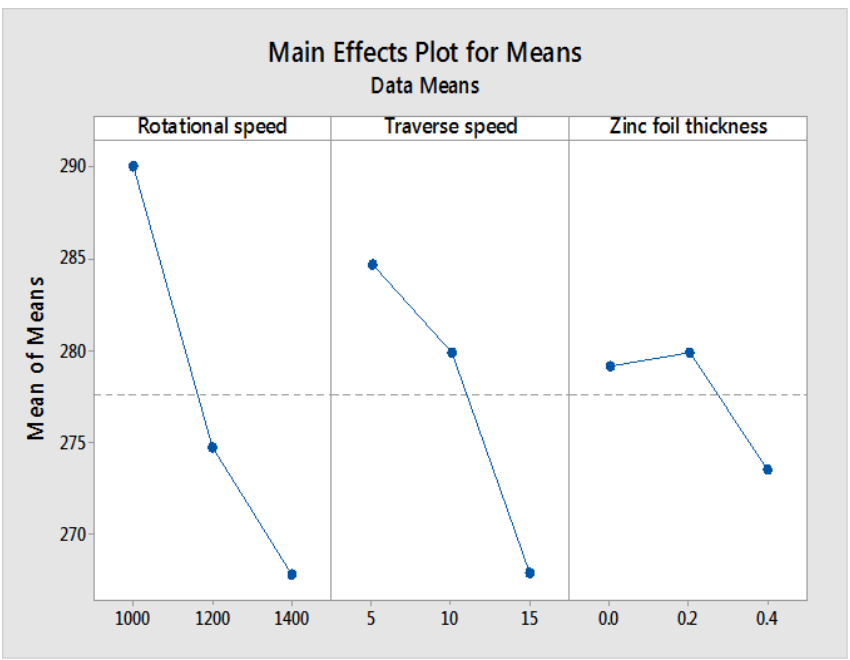

Figure 3. Main effects plot for Means

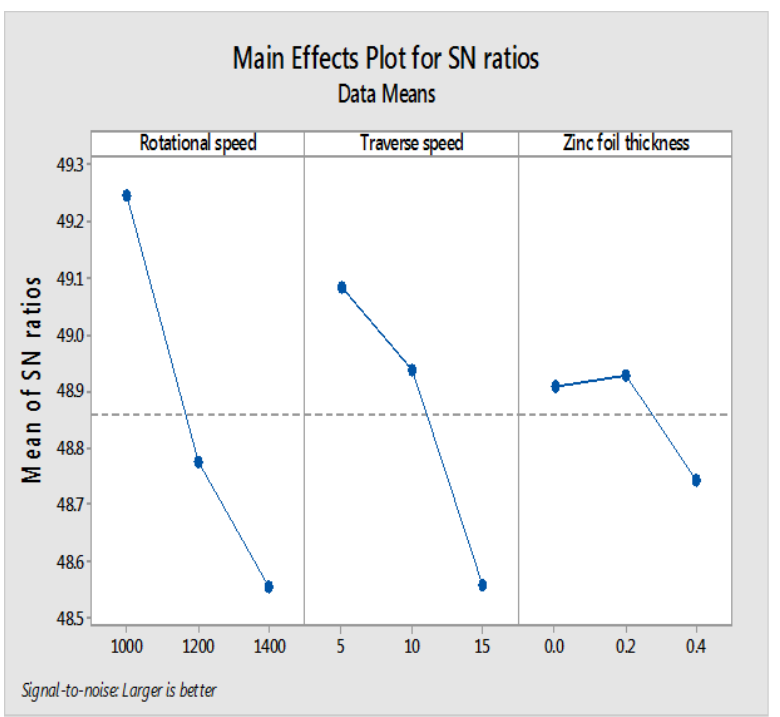

Figure 4. Main effects plot for $\mathrm{SN}$ ratios 


\section{B. Analysis of variance (ANOVA)}

The analysis of variance is used to evaluate the significant effect of process parameters on thermal conductivity. The results from ANOVA of means and ANOVA of signal to noise ratios are shown in Table VII. and Table VIII. respectively. F-test measures the effect of process parameters the quality characteristic. Generally, when $\mathrm{F}$ is greater than 4, it implies that the quality characteristic is significantly affected by the process parameter. In this investigation, tool traverse speed and the zinc foil thickness were the most significant factors contributing to the thermal conductivity of the weld.

VII. Analysis of Variance for Means

\begin{tabular}{llllll}
\hline Source & DF & Seq SS & $\begin{array}{l}\text { Adj } \\
\text { MS }\end{array}$ & F & $\begin{array}{l}\% \\
\text { Contribution }\end{array}$ \\
\hline A & 2 & 781.64 & 390.8 & 354.2 & 59.84 \\
B & 2 & 451.08 & 225.5 & 201.4 & 34.53 \\
C & 2 & 71.31 & 35.65 & 32.31 & 5.46 \\
Residual & 2 & 2.21 & 1.103 & & 0.084 \\
Error & & & & & 100 \\
Total & 8 & 1306.2 & & & \\
\hline
\end{tabular}

VIII. Analysis of Variance for signal to noise ratios

\begin{tabular}{llllll}
\hline Source & DF & $\begin{array}{l}\text { Seq } \\
\text { SS }\end{array}$ & $\begin{array}{l}\text { Adj } \\
\text { MS }\end{array}$ & F & $\begin{array}{l}\% \\
\text { Contribution }\end{array}$ \\
\hline A & 2 & 0.75 & 0.371 & 198.6 & 59.67 \\
B & 2 & 0.441 & 0.22 & 116.7 & 35.06 \\
C & 2 & 0.062 & 0.031 & 16.52 & 4.96 \\
Residual & 2 & 0.003 & & & 0.30 \\
Error & 2 & & & 100 \\
Total & 8 & 1.257 & 0.001 & & \\
\hline
\end{tabular}

$\mathrm{DF}=$ degrees of freedom, Seq SS = sequential sum of squares, Adj MS = adjusted mean square, $\mathrm{F}=$ fisher ratio.

\section{Determination of the maximum thermal conductivity}

From the experiments, the optimal level is set as $A_{1} B_{2} C_{2}$. The average value $(\mathrm{T})$ is taken from Table $\mathrm{V}$. andthe predicted value of the response is computed.

Thermal conductivity $=\mathrm{A} 1+\mathrm{B} 1+\mathrm{C} 2-2 \mathrm{~T}$

$=290.1+284.8+279.9-2$ X $277.57=299.66 \mathrm{~W} /(\mathrm{m} . \mathrm{K})$

where $A_{1}$ is the average value of tool rotational speed at $1^{\text {st }}$ level, $B_{1}$ is average value of tool transverse speed at $1^{\text {st }}$ level, and $C_{2}$ is average value of thickness of zinc inter-filler material at $2^{\text {nd }}$ level..

\section{Confirmation test}

The improvement in quality characteristic is confirmed by using the optimum level of design parameters. The tool rotational speed, tool traverse speed, zinc foil thickness were set at $1000 \mathrm{rpm}, 5 \mathrm{~mm} / \mathrm{min}$ and $0.2 \mathrm{~mm}$ respectively. The average thermal conductivity value of the FSWed AA6063 and ETP copper is $292.1 \mathrm{~W} /(\mathrm{m} . \mathrm{K})$.

\section{CONCLUSION}

Friction stir lap welds were performed to join AA6063 and ETP copper plates. The findings are as concluded below:

1) Taguchi optimization technique was employed to obtain the optimal levels of process parameters in FSW. The optimal levels of tool rotational speed, tool traverse speed and thickness of zinc inter-filler material are $1000 \mathrm{rpm}, 5$ $\mathrm{mm} / \mathrm{min}$, and $0.2 \mathrm{~mm}$ respectively.

2) It is observed that the tool rotational speed, tool traverse speed and thickness of zinc inter-filler contribute $59.84 \%, 34.53 \%$, and $5.46 \%$ respectively to the thermal conductivity of welded joints, wherein noise contributed $0.084 \%$.

Using confirmation test, a $2.53 \%$ error was observed between the experimental and predicted value of the thermal conductivity of welded joints.

\section{REFERENCES}

1. P. Xue, B. L. Xiao, D. Wang, and Z. Y. Ma, "Achieving high property friction stir welded aluminium/copper lap joint at low heat input," Science and Technology of Welding and Joining, vol. 16, no. 8, pp. 657-661, Nov. 2011.

2. K. P. Mehta and V. J. Badheka, "A Review on Dissimilar Friction Stir Welding of Copper to Aluminum: Process, Properties, and Variants," Materials and Manufacturing Processes, vol. 31, no. 3, pp. 233-254, Feb. 2016.

3. H. Wei, A. Latif, G. Hussain, B. Heidarshenas, and K. Altaf, "Influence of Tool Material, Tool Geometry, Process Parameters, Stacking Sequence, and Heat Sink on Producing Sound Al/Cu Lap Joints through Friction Stir Welding," Metals, vol. 9, no. 8, p. 875, Aug. 2019.

4. E. T. Akinlabi, A. Andrews, and S. A. Akinlabi, "Effects of processing parameters on corrosion properties of dissimilar friction stir welds of aluminium and copper," Transactions of Nonferrous Metals Society of China, vol. 24, no. 5, pp. 1323-1330, May 2014.

5. "Selection Of Heat Sink Materials | Power Products International."

6. M. Shaira and S. Yousef, "Modification of Aluminium 6063 Microstructure by Adding Boron and Titanium to Improve the Thermal Conductivity," Journal of Materials, 2018.

7. TechnischeUniversitaetMuenchen Press Release, "Aluminum to replace copper as a conductor in on-board power systems," ScienceDaily, Germany, 07-Feb-2011.

8. Onstad, E., Obayashi, Y., and Shamseddine, R., "Auto, power firms save millions swapping copper for aluminum," Reuters, 15-Mar-2016.

9. B. S. Yilbaş, A. Z. Şahin, N. Kahraman, and A. Z. Al-Garni, "Friction welding of St-Al and $\mathrm{Al}-\mathrm{Cu}$ materials," Journal of Materials Processing Technology, vol. 49, no. 3, pp. 431-443, Feb. 1995.

10. M. Sahin, "Joining of aluminium and copper materials with friction welding," Int J AdvManufTechnol, vol. 49, no. 5-8, pp. 527-534, Jul. 2010.

11. S. Matsuoka and H. Imai, "Direct welding of different metals used ultrasonic vibration," Journal of Materials Processing Technology, vol. 209, no. 2, pp. 954-960, Jan. 2009.

12. M. G. Jones, "Laser welding aluminum to copper," US4224499 A, 23-Sep-1980.

13. A. Esmaeili, H. Z. Rajani, M. Sharbati, M. B. Givi, and M. Shamanian, "The role of rotation speed on intermetallic compounds formation and mechanical behavior of friction stir welded brass/aluminum 1050 couple," Intermetallics, vol. 19, no. 11, pp. 1711-1719, 2011.

14. R. S. Mishra and Z. Y. Ma, "Friction stir welding and processing," Materials Science and Engineering: R: Reports, vol. 50, no. 1, pp. 1-78, 2005. 
15. W. M. Thomas, E. D. Nicholas, J. C. Needham, M. G. Murch, P. Temple-Smith, and C. J. Dawes, "Friction welding," US5460317 A, 24-Oct-1995.

16. W. M. Thomas and E. D. Nicholas, "Friction stir welding for the transportation industries," Materials \& Design, vol. 18, no. 4-6, pp. 269-273, Dec. 1997.

17. A. Elrefaey, M. Takahashi, and K. Ikeuchi, "Preliminary investigation of friction stir welding aluminium/copper lap joints," Weld. World, vol. 49, no. 3-4, pp. 93-101, 2005.

18. A. Elrefaey, M. Takahashi, and K. Ikeuchi, "Microstructure of aluminum/copper lap joint by friction stir welding and its performance," Journal of High Temperature Society, vol. 30, no. 5, pp. 286-292, 2004.

19. D. Devaiah, K. Kishore, and P. Laxminarayana, "Optimal FSW process parameters for dissimilar aluminium alloys (AA5083 and AA6061) Using Taguchi Technique," Materials Today: Proceedings, vol. 5, no. 2, Part 1, pp. 4607-4614, Jan. 2018.

20. M. Muthu Krishnan, J. Maniraj, R. Deepak, and K. Anganan, "Prediction of optimum welding parameters for FSW of aluminium alloys AA6063 and A319 using RSM and ANN," Materials Today: Proceedings, vol. 5, no. 1, pp. 716-723, 2018.

21. G. Ugrasen, G. Bharath, G. K. Kumar, R. Sagar, P. R. Shivu, and R. Keshavamurthy, "Optimization of Process Parameters for Al6061-Al7075 alloys in Friction Stir Welding using Taguchi's Technique," Materials Today: Proceedings, vol. 5, no. 1, Part 3, pp. 3027-3035, Jan. 2018.

22. M. H. Shojaeefard, A. Khalkhali, M. Akbari, and M. Tahani, "Application of Taguchi optimization technique in determining aluminum to brass friction stir welding parameters," Materials \& Design (1980-2015), vol. 52, pp. 587-592, Dec. 2013.

23. B. Kuang et al., "The dissimilar friction stir lap welding of 1 A99 Al to pure Cu using $\mathrm{Zn}$ as filler metal with 'pinless' tool configuration," Materials \& Design, vol. 68, pp. 54-62, Mar. 2015.

24. S. Datta, A. Bandyopadhyay, and P. K. Pal, “Application of Taguchi philosophy for parametric optimization of bead geometry and HAZ width in submerged arc welding using a mixture of fresh flux and fused flux," The International Journal of Advanced Manufacturing Technology, vol. 36, no. 7-8, pp. 689-698, 2008. 